\title{
Pigeons discriminate pictures of a geographic location
}

\author{
DONALD M. WILKIE, ROBERT J. WILLSON, and SHAYNE KARDAL \\ University of British Columbia, Vancouver, British Columbia, Canada
}

\begin{abstract}
Four pigeons previously trained to home to the roof of the University of British Columbia psychology building and 4 nonhoming pigeons were trained to discriminate between two sets of color slides projected onto a pecking panel of a Skinner box. One slide set consisted of photographs taken in the vicinity of the psychology building; the other set consisted of similar views taken at locations not previously visited by the homing subjects. All subjects were rewarded for pecking during slides from the first but not the second set. Every few sessions, new "Home" and "Away" slides were introduced during transfer tests. In a final transfer test, a completely new tray of Home and Away slides was introduced. The homing pigeons were slightly (but not statistically significantly) better at discriminating Home from Away slides. The implications of these results for understanding pigeons' homing behavior, concept attainment, and spatial memory are dis cussed.
\end{abstract}

Pigeons appear to be able to form conceptual discriminations based on photographs of such natural objects as people, fish, water, trees, and leaves (see Herrnstein, 1984 , for a review). In these studies, pigeons were rewarded for pecking at projected images that contained the target object (e.g., a tree), and were not rewarded for pecking at images in which the target was absent. Typically, pigeons learned these discriminations rapidly, showed good transfer to novel instances of the target category, and remembered these discriminations over periods of many months (e.g., Vaughan \& Greene, 1984). Pigeons seemed to treat these two-dimensional projected images as if they represented "real" three-dimensional objects. Both Cabe (1976) and Lumsden (1977) have shown that pigeons transfer discriminations of actual objects to photographs of the same objects. In addition, Looney and Cohen (1974) have shown that pigeons will attack photographs of conspecifics in situations in which aggressive responding is normally elicited. Perhaps the most convincing evidence that birds treat photographic projections as if these images were actual objects comes from a study of Roberts and Weigl (1984). In that study, investigators tested wild-caught dark-eyed juncos in a test chamber that contained two perches mounted on end walls containing projection screens. Images of this species' distinctive summer and winter habitats were projected onto the two screens, and the subjects' preference for an image was measured by recording how much time they spent

\footnotetext{
This research was supported by the Natural Sciences and Engineering Research Council of Canada. John Zahradnik kindly donated racing homing pigeons whose offspring served as subjects in this research. C. Von Borman greatly assisted with the data analysis. Send correspondence regarding this paper to Donald M. Wilkie, Department of Psychology, University of British Columbia, Vancouver, British Columbia V6T 1Y7, Canada, or the following E-Mail address: userdonw@mtsg.ubc.ca.
}

on the perch in front of the respective image. Roberts and Weigl found that winter-caught birds preferred the winter slides (images of an open forest of pine and hardwood trees), whereas summer-caught birds preferred the summer slides (images of a mixed grassland-conifer forest). They also found that preferences were controlled by the photoperiod of colony light cycle. Preference for winter slides increased when the colony was lit for $9 \mathrm{~h}$ and was dark for $15 \mathrm{~h}$. Preference for the summer slides increased when the colony was illuminated for $15 \mathrm{~h}$.

Roberts and Weigl's (1984) results suggested to us that a variant of their methodology might be useful to investigate whether or not pigeons can visually recognize a geographic location represented in pictures. An answer to this question is important for three reasons.

First, geographic location (e.g., trees, fish, etc.) is a natural stimulus, and it is interesting to know if pigeons are capable of forming a conceptual discrimination with this type of stimulus. At the time we began this study, there was no evidence that pigeons could make such a discrimination. However, during the course of our study, Honig and Stewart (1988) demonstrated that pigeons could discriminate slides taken at one spot on a university campus from slides taken at another location. Our experiment systematically replicates and extends this finding.

The second reason for this study concerns the validation of laboratory methodologies and concepts employed to investigate animals' processing of spatial information. In laboratory paradigms used to study processes such as spatial memory, "place" is typically very narrowly defined (e.g., an arm of a maze, or a platform in a pool of water) in an environment (e.g., a laboratory room) that is rather impoverished of stimuli and that does not contain such cues as sky, horizon, and vegetation that occur in natural, geographic places. A demonstration that subjects can discriminate a particular geographic place and 
remember this information would bolster our confidence in our current approaches to the study of animals' processing of spatial information.

The third reason our study is of importance bears on the long-standing and unresolved issue of whether homing pigeons use visual recognition of place during navigation. There have been several roadblocks to resolving this issue. One problem has been the heavy reliance on observational rather than experimental procedures. Although observational procedures are certainly useful in characterizing pigeons' homing behavior, they are not useful in testing such specific hypotheses as whether pigeons use visual recognition of places during homing. Occasionally, the same set of observational data has been interpreted as showing that homing pigeons do (Michener \& Walcott, 1967) or do not (Murray, 1967) rely on visual landmarks. Another problem has been that, even when experimental manipulations have been used, the results have been ambiguous. If pigeons reach home by a process of visually recognizing places, they should not be influenced by a disruption of the magnetic field (by attaching small magnets to the bird). Although initial studies (e.g., Keeton, 1971) suggested that magnetic-field disturbance disrupted homing, later studies have seriously questioned this conclusion (see the special section in the May 1987 issue of Animal Learning \& Behavior).

A more direct test of whether homers use visual information was performed by Schmidt-Koenig and Schlichte (1972), who released pigeons fitted with frosted contact lenses. They found that these birds were able to orient in the homeward direction correctly, but were often unable to reach their lofts successfully. These results were initially interpreted as showing that visual information was not necessary for initial orientation at a release site, but was only important close to home. However, there has been some concern expressed with just how opaque the contact lenses were (Baker, 1984; Benvenuti \& Fiaschi, 1983)

A demonstration that pigeons can discriminate pictures of actual geographic places would provide converging evidence that homing pigeons may use visual recognition of landmarks and topography, at least when they are close to home. In the research described below, we asked if pigeons could discriminate pictures taken in the immediate vicinity of the "loft" to which they had been trained to home. To determine if actual homing experience was necessary for this discrimination, a group of nonhoming pigeons was also tested.

\section{Subjects}

\section{METHOD}

Eight pigeons served as subjects. Except during periods of homing training, the subjects were housed singly in large plastic mesh cages where they had free access to water, crushed oyster shells, and health grit. The pigeons received sufficient mixed grain daily to maintain their body weights at about $90 \%$ of normal. The light cycle in the colony was adjusted every few days so that light onset and offset matched actual sunrise and sunset times.

Nonhoming pigeons. Three of these subjects were hybrid King pigeons obtained from Vancouver Island Mountain Squab, Nanaimo,
B.C., Canada. The 4th subject was an offspring of racing homing pigeons. None of these subjects had ever left the building that contained their colony and testing rooms.

Homing pigeons. These subjects were 4 of a flock of 5 pigeons that received homing training during May and June of 1987. These birds were offspring of racing homers, and were hatched in our colony. The subjects were weaned at approximately 5 weeks of age, at which time they were housed as a group in a large plastic mesh $(65 \times 80 \times 53 \mathrm{~cm})$ cage. A floor-level one-way trap door was located on the front wall of this cage. The subjects were initially trained in the colony to enter the cage quickly via the trap door. Once this training was complete, the subjects were transported in a small holding cage to the roof of the psychology building, where they were placed in a cage identical to their home cage. The birds were left in this cage from approximately 0900 to $1400 \mathrm{~h}$, and were then returned to the colony. This procedure was repeated on a total of 6 days. In this and all subsequent phases of homing training, the subjects were taken outside only on days that were mainly sunny.

The subjects next received free-flight training. The pigeons were released from the building rooftop, as a group, at about $0900 \mathrm{~h}$ on 7 different days. On these days, the birds typically flew as a flock in circles above the roof of the building, and were never observed to venture more than a few hundred meters from the building. On these and all subsequent free-flight days, the subjects were deprived of food on the day before the flight. On flight days, the rooftop cage contained sufficient mixed grain to enable each bird to eat until satiated. The birds were returned to the colony after all subjects had reentered the cage.

Subsequent to the rooftop releases, the birds were released as a group four times from four different sites, for a total of 16 releases. The four release sites were progressively more distant from the psychology building. All release sites were large, open grassy areas. The first release site was a playing field on campus $1.5 \mathrm{~km}$ and $130^{\circ}$ (SE) from the psychology building. The second site was an oceanside park $4.1 \mathrm{~km}$ and $75^{\circ}$ from home. The third site was a playing field $7.8 \mathrm{~km}$ and $114^{\circ}$ from home. The fourth site was a park $17.8 \mathrm{~km}$ and $105^{\circ}$ from home. From all sites except the first, the birds had to traverse residential areas and the forested area that surrounds the University of British Columbia (UBC) campus. At each release site, the flock typically flew in circles a few times before vanishing in a general homeward direction. The elapsed time between release and spotting by a rooftop observer decreased after the first release from the first $(12,4,2.5$, and $5 \mathrm{~min})$ and second sites $(35,31,12$, and $13 \mathrm{~min})$ but not from the third (elapsed times of about $13 \mathrm{~min}$ ) or fourth (elapsed times of abour $18 \mathrm{~min}$ ) sites. Interspersed with these distant releases were 10 additional rooftop releases.

\section{Apparatus}

A Kodak 850 Carousel slide projector was mounted $19 \mathrm{~cm}$ above the floor and $35 \mathrm{~cm}$ from a testing box. The projector produced a $15 \times 12 \mathrm{~cm}$ image on a piece of $16 \times 15 \mathrm{~cm} \mathrm{T-31}$ frosted Plexiglas that was mounted $16 \mathrm{~cm}$ above the floor and centered on the front wall of the testing box. The Plexiglas was hinged on the wall in such a way that if the pigeon pecked the image, the Plexiglas would close a microswitch that was also mounted on the wall. Also on the front wall was a $5 \times 5 \mathrm{~cm}$ opening, centered $8 \mathrm{~cm}$ above the floor, that allowed the pigeon access to a food hopper. The back and side walls of the testing box $(39 \times 41 \times 40 \mathrm{~cm})$ were made of $1 \mathrm{~cm}$ plywood; the front wall and lid were made of $.6 \mathrm{~cm}$ clear Plexiglas. The testing box and slide projector sat on a table located in a dimly lit, sound attenuating room. The slide projector, hopper, and response switch were all connected to and controlled by a Data General Nova 3 computer located in another room.

Slides. Ninety-six 35-mm color slides were taken at f16 with a 50-mm lens on several clear, sunny days during the spring and summer of 1987. Half of the pictures were taken in the immediate vicinity (within a few hundred meters) of the area to which our hom- 
ing pigeons flew ("Home"). The remaining slides were similar, but were taken at locations to which our homing pigeons had not been exposed ("Away"). Approximately half of each type of slide were Kodachrome; the others were Fujichrome.

The Home slides consisted of several types of shots. Several shots were taken from the roof of the psychology building. In some of these slides, rooftop structures, including a blue metal-framed glass atrium, figured prominently. In some, but not all of these shots, the distant horizon was visible. Oher rooflop shots were panoramic. These were taken in all directions and showed campus buildings, vegetation, and parking lots that surround the psychology building. In some shots to the west, the Gulf of Georgia of the Pacific was visible. In shots to the northwest, north, and northeast, some of the coastal mountains were prominent. Another type of shot was taken from areas adjacent to the psychology building and were focused on the building. Some of these were ground-level pictures; more commonly these were taken from the rooftops of neighboring buildings.

The Away slides consisted of similar shots. These slides were taken at four different locations: in areas of Vancouver known not to have been visited by the homers, on the campuses of Dalhousie University (Halifax, Nova Scotia) and the University of Lethbridge (Lethbridge, Alberta), and in a high-rise area in Toronto, Ontario.

Figure 1 shows four Home slides; Figure 2 shows four Away slides. The left-hand slides in both figures are ones that the subjects discriminated easily; the slides on the right were difficult for the subjects to discriminate (see Results below). In the Home slide figure, the upper-left slide was taken from the location of the rooftop cage. The lower-left slide is another shot taken from the rooftop of the psychology building. The lower-right slide is a shot of a building on the UBC campus. The upper-right slide is an easterly
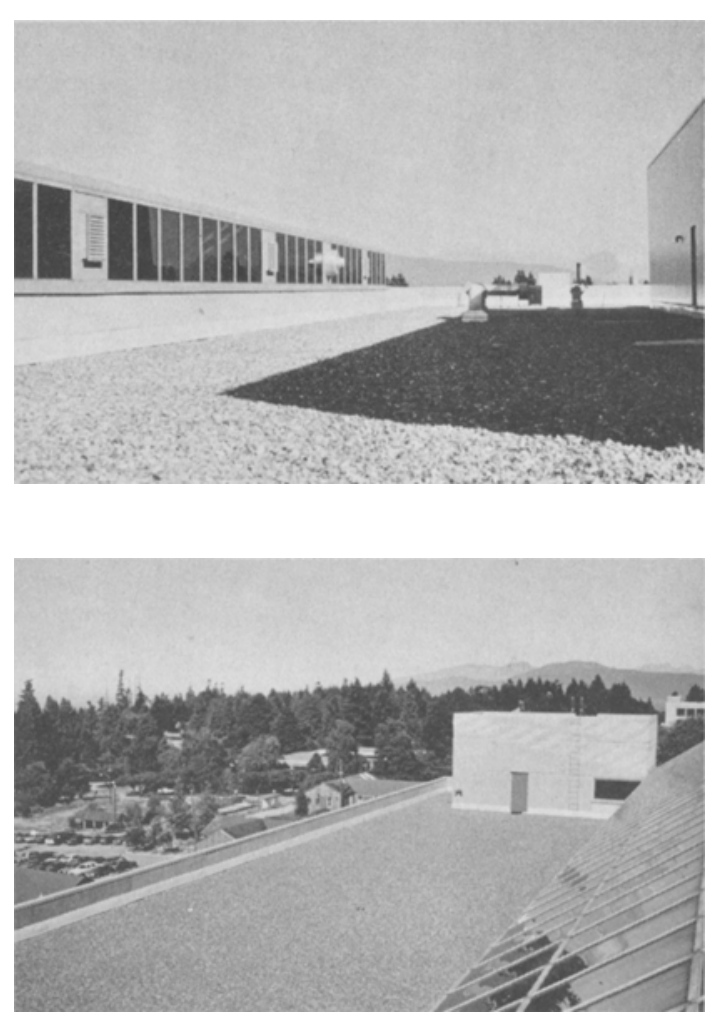

panoramic shot of part of the UBC campus. The upper-right and left-hand slides in Figure 2 are from locations on the Dalhousie campus. The lower-right slide was taken on the University of Lethbridge campus.

\section{Procedure}

During slide-discrimination training, the homing pigeons were released periodically for spontaneous flights. These flights were halted after the third transfer test (see below), when fall weather deteriorated.

Initial training. All birds received 3 days of magazine training during which time they were trained to eat from an automated grain hopper. Once a bird was eating reliably from the hopper, an autoshaping procedure was initiated. All birds were initially conditioned to peck at a small $(2.5 \mathrm{~cm}$ diameter) green circle (the CS) projected onto the panel of the Skinner box. The CS was illuminated for $8 \mathrm{sec}$ and followed immediately by 6-sec access to the grain hopper. If the subject pecked at the CS during this 8-sec interval, the circle was turned off and access to the grain hopper began immediately. Subjects received 32 autoshaping trials per day. Once a subject began to keypeck, grain access was made contingent on this response. After a subject was responding reliably (making a response within $8 \mathrm{sec}$ on 25 of 32 trials) to the green circle, the CS was changed to a white square $(2.5 \times 2.5 \mathrm{~cm})$, and the size of this square was increased on successive days until it covered the entire panel of the Skinner box. Once a subject was responding reliably to this $\mathrm{CS}$, training with slides began. The actual number of days for completion of the initial training varied, but it did not take more than 10 days for any subject.

One-slide training. During this phase of training, the pecking panel was constantly illuminated by a color slide of the roof area
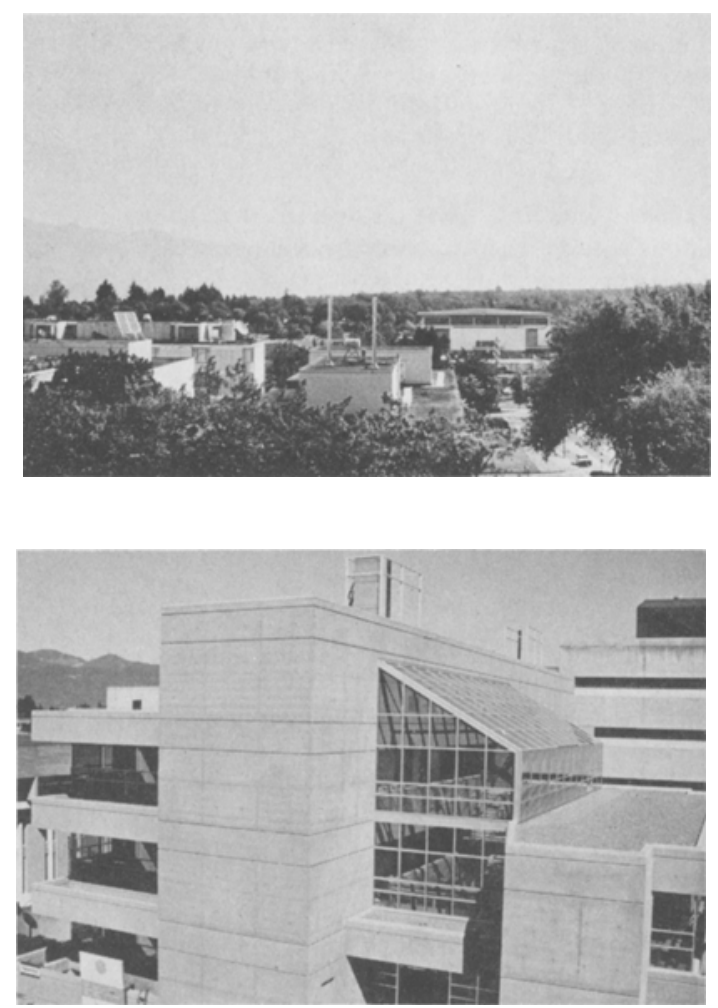

Figure 1. Four "Home" slides. The two left-hand slides are ones that subjects discriminated easily; the right-hand slides were dificult for the subjects to discriminate. The top-left slide corresponds to Position 11 in Table 3 , the bottom-left slide to Position 8, the top-right slide to Position 3, and the bottom-right slide to Position 10. 

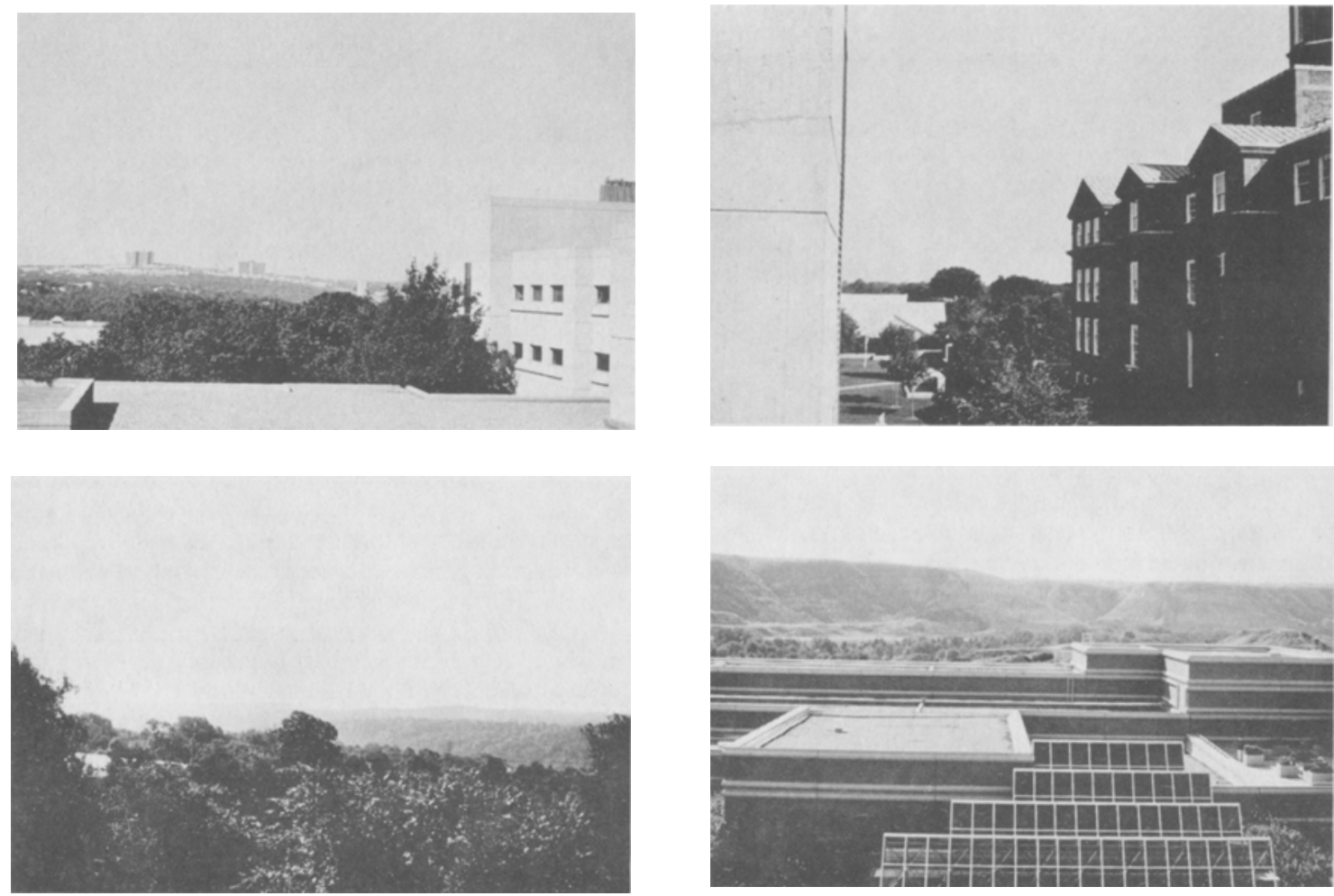

Figure 2. Four "Away" slides. The two left-hand slides are ones that subjects discriminated easily; the right-hand slides were difficult for the subjects to discriminate. The top-left slide corresponds to Position 23 in Table 4 , the bottom-left slide to Position 17, the top-right slide to Position 2, and the bottom-right slide to Position 13.

of the psychology building. Once a subject was responding reliably to this initial slide, the response requirement was slowly incremented until the subject was making an average of 10 responses for every reinforcer. At this point, a short fixed-interval $(8 \mathrm{sec})$ schedule was introduced, and the first response following the end of the interval resulted in 6-sec access to mixed grain. This interval was slowly incremented until the subject was responding at a stable rate over a 20 -sec interval. This phase took about 3 days.

Discrimination training. During the next phase, seven additional slides were introduced, three more slides of the UBC campus and surrounding area (Home; the " $S+$ " slides) and four others of locations known not to have been seen by the homing subjects (Away; the " $S$-" slides). All slides were presented for $20 \mathrm{sec}$ and responses were recorded throughout this interval. On $\mathbf{S}+$ trials, the first response following this 20 -sec interval was reinforced with 6-sec access to grain. A 0.5 -sec intertrial interval (ITI), during which time the projection panel was darkened, followed the reinforcement. On S- trials, the 20-sec slide presentation was directly followed by the ITI. At the end of each session, a discrimination ratio (DR $=A / A+B$, where $A$ is the number of responses to $S+$ and $B$ is the number of responses to $S-$ ) was calculated. Training with these slides continued for 12 sessions.

Transfer tests. From this point onward, four new slides (two $S+$ and two $S-$ ) were added every 5 days, until a total of $24 S+$ slides and $24 \mathrm{~S}$ - slides were being presented during each session Following five sessions with 48 slides (the 10th transfer test), all subjects were exposed to a completely new set of 48 slides (24 S+ and $24 \mathrm{~S}-$ ) for an additional 3 days.
Retention test. Sixty days after the end of the previous phase, each subject received two additional sessions, one with each set of 48 slides. The original training set was always presented first, followed by the transfer set.

\section{RESULTS}

The pigeons rapidly learned the initial eight-slide discrimination. After only 12 sessions of training ( $48 \mathrm{~S}+$ trials, $48 \mathrm{~S}$ - trials; approximately $30 \mathrm{~min}$ of training), discrimination ratios were about .80 (see Figure 3 ). The homing pigeons tended to discriminate slightly better than the nonhomers, but this difference was not statistically significant. In a 2 -group $\times 12$-days analysis of variance (ANOVA), neither the group effect $[F(1,6)=2.14, p=$ .19] nor the group $\times$ days interaction $[F(11,66)=1.30$, $p=.25]$ was significant. However, there was a large days effect $[F(11,66)=6.04, p<.001]$.

Figures 4 and 5 show discrimination ratios for the homing and nonhoming subjects during the 10 transfer tests and when a completely new tray of slides was introduced. During each transfer test, some of the slides were pictures on which the subjects had been previously trained. Discrimination ratios for these "old" slides are shown in Figure 4. In each transfer test, four new slides (two 
FIRST EIGHT SLIDES

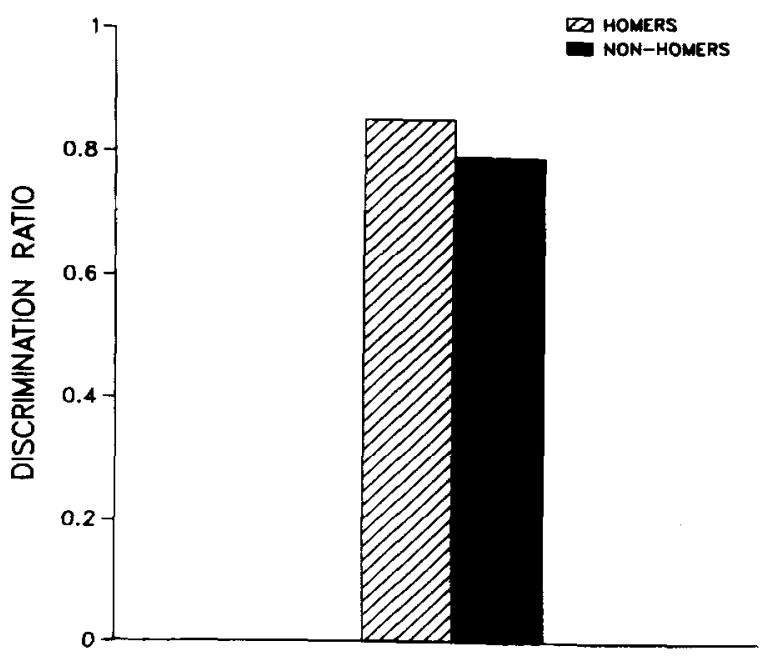

Figure 3. Discrimination ratios of homing and nonhoming subjects during the last three sessions of initial training with eight slides.

$\mathrm{S}+$, two $\mathrm{S}-$ ) were also presented. Discrimination ratios for these "new" slides are shown in Figure 5. The data in Figures 4 and 5 are from the first day only of each transfer phase. Thus, discrimination ratios in Figure 5 are for slides that the subjects were viewing for the very first time. Both homer and nonhomer groups had high discrimination ratios on old slides during each of the 10 transfer tests (Figure 4). Discrimination ratios on the slides being viewed for the first time were not as high as for slides previously seen, but were generally much higher than chance levels. (The lower discrimination ratios on Transfer Tests 7 and 9 are discussed below.) The better discrimination shown in acquisition by the homers was again evident during the first three transfer tests. This difference was statistically significant $[F(1,6)=6.09, p=$ $.0477]$ in an old/new $\times$ transfer test $\times$ group ANOVA. It is interesting to note that at this point in the experiment, the homing pigeons were still being given occasional outdoor flight training. After the third transfer test, outdoor flights ceased due to inclement weather. After this point, the performance of the two groups converged. An ANOVA of the discrimination ratios over the whole set of transfer tests revealed no difference between groups $[F(1,6)=1.56, p=.26]$. There was an old/new slide effect $[F(1,6)=10.6, p=.017]$, which confirms that old slides were discriminated better than new ones. Performance differed across the transfer tests $[F(9,54)=$ $5.61, p<.001]$. Post hoc Newman-Keuls tests revealed that performance on Test 7 was significantly lower than performance on all other tests. There was no group $x$ test interaction $[F(9,54)=1.11, p=.37]$.

Discrimination ratios based on all 5 transfer days are shown in Table 1. The pattern of results based on all 5 days is similar to that for the first day. ANOVA of these data showed no group effect $[F(1,6)=1.81, p=.23]$, buc revealed an old/new slide effect $[F(1,6)=6.93$, $p=.04]$ and a test effect $[F(9,54)=7.15, p<.001]$. Again, there was no group $\times$ test interaction $[F(9,54)=$ $1.79, p=.09]$.

Discrimination ratios for the first day of exposure to the completely new tray of slides are also shown in Figure 5. The nonhomer group discriminated these slides slightly, but significantly $[t(6)=-3.02, p=.039]$, better than did the homer group. The difference between

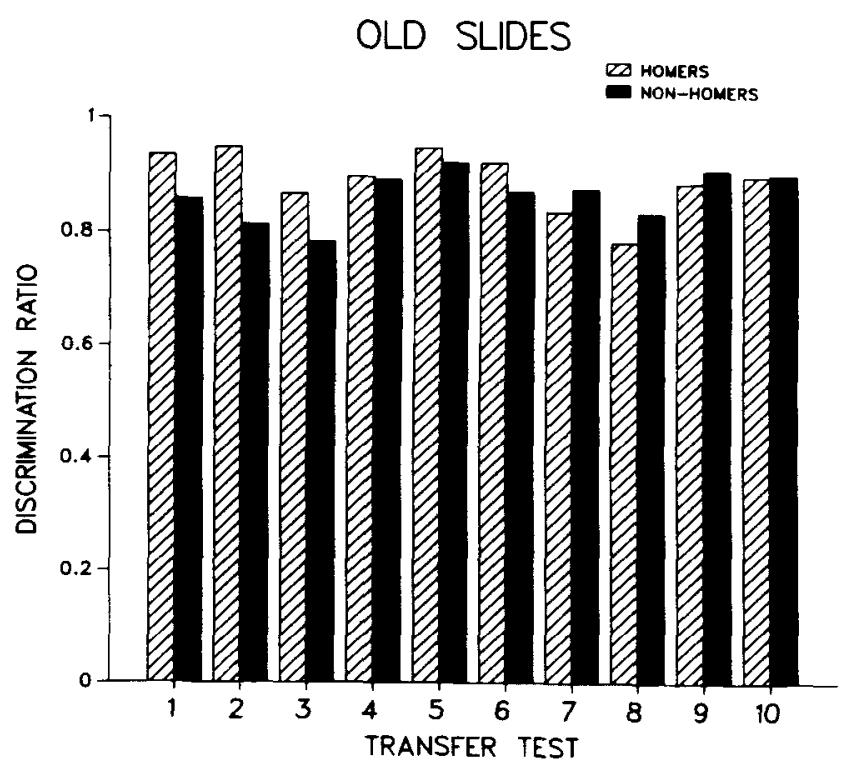

Figure 4. Discrimination ratios of homing and nonhoming subjects during the first session of each transfer test for slides the subjects had previously seen.

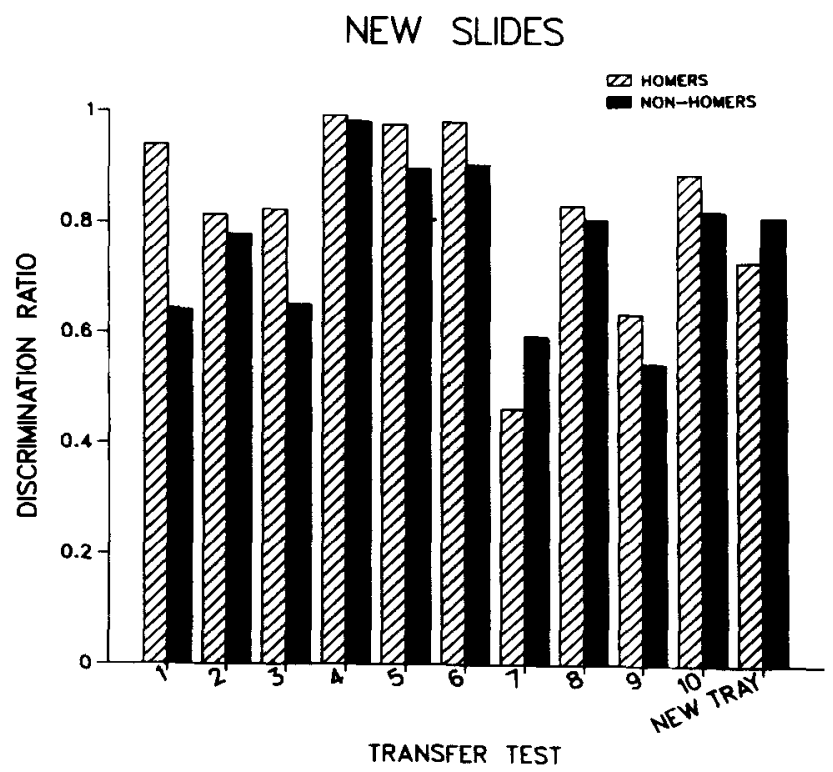

Figure 5. Discrimination ratios of homing and nonhoming subjects during the first session of each transfer test for new slides. 
Table 1

Discrimination Ratios Based on All Sessions in Each Transfer Test

\begin{tabular}{cccccc} 
& \multicolumn{2}{c}{ Homers } & & \multicolumn{2}{c}{ Nonhomers } \\
\cline { 2 - 3 } \cline { 5 - 6 } Test & $\begin{array}{c}\text { Old } \\
\text { Slides }\end{array}$ & $\begin{array}{c}\text { New } \\
\text { Slides }\end{array}$ & $\begin{array}{c}\text { Old } \\
\text { Slides }\end{array}$ & $\begin{array}{c}\text { New } \\
\text { Slides }\end{array}$ \\
\hline 1 & .90 & .88 & .77 & .70 \\
2 & .85 & .84 & .80 & .80 \\
3 & .90 & .92 & .84 & .73 \\
4 & .92 & .97 & .90 & .96 \\
5 & .96 & .97 & .93 & .88 \\
6 & .91 & .92 & .88 & .95 \\
7 & .87 & .61 & .90 & .65 \\
8 & .88 & .87 & .89 & .90 \\
9 & .93 & .78 & .88 & .71 \\
10 & .91 & .92 & .89 & .88 \\
\hline
\end{tabular}

Table 2

Percentage of Transfer-Tray Slides Containing Various Features

\begin{tabular}{lrrr}
\hline Feature & Home Slides & Away Slides & Difference \\
\hline SKY & 100 & 96 & 4 \\
HOR & 88 & 79 & 9 \\
RTS & 100 & 88 & 12 \\
PBD & 54 & 0 & 54 \\
OBD & 83 & 100 & 17 \\
VEG & 96 & 83 & 13 \\
GLV & 4 & 16 & 12 \\
MTN & 54 & 0 & 54 \\
BLU & 67 & 13 & 54 \\
EGT & 70 & 29 & 41 \\
DST & 75 & 83 & 8 \\
WAT & 21 & 4 & 17 \\
CAR & 50 & 29 & 21 \\
GLS & 88 & 63 & 25 \\
ATR & 33 & 25 & 8 \\
CLD & 13 & 33 & 20 \\
SHD & 96 & 92 & 4 \\
\hline
\end{tabular}

Note-Features were: SKY $=$ sky, HOR $=$ distant horizon, RTS $=$ rooftop(s), $\mathrm{PBD}=$ psychology building visible, $\mathrm{OBC}=$ other building(s), $V E G=$ vegetation, GLV $=$ ground level shot, $M T N=$ mountain(s), BLV = blue object(s), EGT = evergreen tree(s), DST $=$ deciduous tree(s), WAT = water, CAR = automobile(s), GLS = glass, ATR $=$ atrium structure, CLD $=$ scattered cloud(s), SHD $=$ shadows.

groups was not significant, however, when discrimination ratios were based on all 3 transfer days [mean DR for homer group $=.79$, mean DR for nonhomers $=.81$; $t(6)=-.86, p=.45]$.

Figure 6 shows discrimination ratios for the first and second tray of slides after the 60-day retention interval. Both groups of pigeons discriminated well after the twomonth break. The subjects discriminated the old-tray slides better than the new-tray slides $[F(1,6)=23.4$, $p=.003$ ]. Again, the difference between groups was not significant $[F(1,6)=.86, p=.39]$. The group $\times$ old $/$ new tray interaction also was not significant $[F(1,6)=5.21$, $p=.06 \mathrm{~J}$.

\section{Detailed Analysis of Discriminations}

The first result examined in more detail was the relatively poor transfer during Tests 7 and 9 . When the slides that comprised these tests were closely examined, it was discovered that each set had one $\mathrm{S}+$ slide that contained reflected sunlight. Thus, image quality, rather than some inherent feature about the place photographed, probably accounts for the relatively poor transfer on Tests 7 and 9.

A second detailed analysis examined responding to individual slides. This analysis was undertaken for two reasons. The first reason was for control purposes. In slide discrimination procedures, it is possible that discriminations are made on the basis of some trivial but consistent difference between the positive and negative set of sides. We wanted to rule out this possible basis of our pigeons' discrimination of a geographic place as best we could. The second reason for this detailed analysis was that we wanted to see if any particular visual feature(s) (e.g., the presence of mountains) were important in discriminating Home slides.

The data chosen for detailed analysis was responding during the first day to the new tray. First, we examined these slides and constructed a list of 17 prominent features that characterized them. These features are listed in Table 2, which shows the percentage of Home and Away slides that contain the various features. Although the features appear with different frequencies in the positive and negative slides, there are no features that are always present in one set but always absent in the other. Thus, at least for the features that were obvious to us in the slides, there is no reason to believe that there was some trivial basis for our subjects' discrimination.

To determine if certain features or sets of features were more important than others, we analyzed each slide for the presence or absence of the features listed in Table 2. We did this for both positive (see Table 3 ) and negative (see Table 4) slides. For each slide, we recorded each subject's response rate and then standardized this rate. The standardized rates were then averaged across subjects. This standardized rate appears in the right-most column

\section{DAY RETENTION TEST}

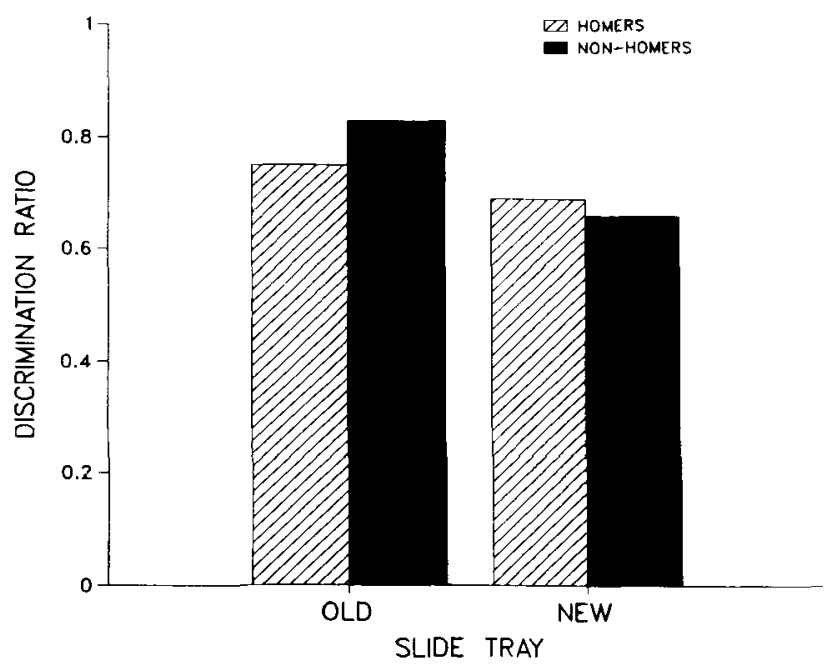

Figure 6. Discrimination ratios of homing and nonhoming subjects during two tests following a 60-day retention interval. 
Table 3

Presence (1) or Absence (0) of 17 Features in 24 Positive Slides

\begin{tabular}{rrrrrrrrrrrrrrrrrrrrrr}
\hline Slide & SKY & HOR & RTS & PBD & OBD & VEG & GLV & MTN & BLU & EGT & DST & WAT & CAR & GLS & ATR & CLD & SHD & $z$ Score \\
\hline 1 & 1 & 1 & 1 & 1 & 1 & 1 & 0 & 0 & 1 & 1 & 0 & 1 & 1 & 1 & 1 & 1 & 1 & -0.56339 \\
2 & 1 & 1 & 1 & 0 & 1 & 1 & 0 & 1 & 1 & 0 & 1 & 0 & 0 & 1 & 0 & 0 & 1 & 0.51100 \\
3 & 1 & 1 & 1 & 0 & 1 & 1 & 0 & 1 & 1 & 0 & 1 & 1 & 1 & 1 & 0 & 0 & 1 & -1.06142 \\
4 & 1 & 1 & 1 & 1 & 0 & 1 & 0 & 0 & 1 & 1 & 1 & 0 & 0 & 1 & 1 & 0 & 1 & 0.93693 \\
5 & 1 & 1 & 1 & 1 & 1 & 1 & 0 & 1 & 1 & 1 & 1 & 0 & 1 & 1 & 1 & 0 & 1 & 0.29401 \\
6 & 1 & 1 & 1 & 0 & 1 & 1 & 0 & 1 & 0 & 1 & 1 & 1 & 1 & 0 & 0 & 0 & 1 & 0.22426 \\
7 & 1 & 0 & 1 & 1 & 1 & 1 & 1 & 0 & 1 & 0 & 1 & 0 & 1 & 1 & 1 & 0 & 1 & -0.61594 \\
8 & 1 & 1 & 1 & 1 & 1 & 1 & 0 & 1 & 1 & 1 & 1 & 0 & 1 & 1 & 1 & 1 & 1 & 0.91004 \\
9 & 1 & 1 & 1 & 1 & 1 & 1 & 0 & 1 & 1 & 1 & 1 & 0 & 0 & 1 & 1 & 0 & 0 & 0.87507 \\
10 & 1 & 1 & 1 & 0 & 1 & 1 & 0 & 1 & 1 & 1 & 1 & 1 & 1 & 1 & 0 & 0 & 1 & -1.05653 \\
11 & 1 & 1 & 1 & 1 & 1 & 1 & 0 & 1 & 1 & 1 & 0 & 0 & 0 & 1 & 1 & 0 & 1 & 1.41492 \\
12 & 1 & 1 & 1 & 0 & 1 & 1 & 0 & 1 & 1 & 1 & 1 & 0 & 1 & 1 & 0 & 1 & 1 & 0.44018 \\
13 & 1 & 0 & 1 & 0 & 1 & 1 & 0 & 0 & 1 & 0 & 1 & 0 & 1 & 1 & 0 & 0 & 1 & 0.24941 \\
14 & 1 & 1 & 1 & 0 & 1 & 1 & 0 & 1 & 1 & 1 & 0 & 0 & 0 & 1 & 0 & 0 & 1 & -0.43608 \\
15 & 1 & 1 & 1 & 0 & 1 & 1 & 0 & 0 & 0 & 0 & 1 & 1 & 1 & 1 & 0 & 0 & 1 & 1.06638 \\
16 & 1 & 1 & 1 & 1 & 1 & 1 & 0 & 0 & 1 & 1 & 0 & 0 & 0 & 1 & 0 & 0 & 1 & 0.13333 \\
17 & 1 & 1 & 1 & 1 & 1 & 1 & 0 & 1 & 0 & 1 & 1 & 0 & 0 & 1 & 0 & 0 & 1 & 0.18288 \\
18 & 1 & 1 & 1 & 0 & 1 & 1 & 0 & 0 & 1 & 1 & 1 & 0 & 1 & 1 & 0 & 0 & 1 & -0.91012 \\
19 & 1 & 1 & 1 & 1 & 0 & 1 & 0 & 0 & 0 & 1 & 0 & 0 & 0 & 0 & 0 & 0 & 1 & -0.09577 \\
20 & 1 & 0 & 1 & 1 & 0 & 1 & 0 & 0 & 0 & 0 & 1 & 0 & 0 & 0 & 0 & 0 & 1 & -0.44955 \\
21 & 1 & 1 & 1 & 1 & 1 & 1 & 0 & 0 & 0 & 1 & 1 & 0 & 0 & 1 & 0 & 0 & 1 & -0.32784 \\
22 & 1 & 1 & 1 & 0 & 1 & 1 & 0 & 1 & 0 & 1 & 1 & 0 & 0 & 1 & 0 & 0 & 1 & -1.09900 \\
23 & 1 & 1 & 1 & 1 & 0 & 0 & 0 & 1 & 1 & 0 & 0 & 0 & 0 & 1 & 1 & 0 & 1 & -0.11626 \\
24 & 1 & 1 & 1 & 0 & 1 & 1 & 0 & 0 & 0 & 1 & 1 & 0 & 1 & 1 & 0 & 0 & 1 & -0.50651 \\
\hline
\end{tabular}

Note-The $z$ score is the standardized rate of responding averaged over all 8 subjects.

of Tables 3 and 4 . A positive $z$ score indicates an aboveaverage response rate; a negative value indicates a belowaverage rate. Thus, for positive slides, a highly positive $z$ score indicates that a slide was a good representation of place. A highly negative $z$ score indicates a poor representation. For negative slides, the opposite is true (e.g., a highly positive $z$ score results from a slide that was difficult to discriminate). An examination of Tables 3 and 4 reveals that there are apparently no particular fea- tures (or simple combinations of features) that made a particular slide easy or hard to discriminate. For example, some positive slides in which the psychology building was absent were difficult (e.g., Slide 22), but others were easy (e.g., Slide 15) to discriminate. It is also clear from examining Table 3 that the presence of the three most distinguishing features of the Home slides (mountains, blue, evergreen trees; see Table 2) did not make a slide easy to discriminate. Slides 4 and 8 , which contained these fea-

Table 4

Presence (1) or Absence (0) of 17 Features in 24 Negative Slides

\begin{tabular}{|c|c|c|c|c|c|c|c|c|c|c|c|c|c|c|c|c|c|c|}
\hline Slide & SKY & HOR & RTS & PBD & OBD & VEG & GLV & MTN & BLU & EGT & DST & WAT & CAR & GLS & ATR & CLD & SHD & $z$ Score \\
\hline 1 & 0 & 0 & 0 & 0 & 1 & 0 & 0 & 0 & 0 & 0 & 0 & 0 & 0 & 1 & $\mathbf{0}$ & 0 & 0 & -0.28761 \\
\hline 2 & 1 & 1 & 1 & 0 & 1 & 1 & 0 & 0 & 0 & 0 & 1 & 0 & 0 & 1 & 1 & 1 & 1 & 1.05958 \\
\hline 3 & 1 & 1 & 0 & 0 & 1 & 1 & 1 & 0 & 0 & 0 & 1 & 0 & 0 & 1 & 1 & 1 & 1 & 0.40546 \\
\hline 4 & 1 & 1 & 1 & 0 & 1 & 1 & $\mathbf{0}$ & 0 & 0 & 1 & 1 & 1 & 0 & 0 & 0 & 1 & 1 & 2.27700 \\
\hline 5 & 1 & 1 & 1 & 0 & 1 & 1 & 0 & 0 & 0 & 1 & 1 & 0 & 1 & 1 & 0 & 0 & 1 & -0.44128 \\
\hline 6 & 1 & 1 & 1 & 0 & 1 & 0 & 0 & 0 & 0 & 0 & 0 & o & 0 & o & 0 & 1 & 1 & 1.15476 \\
\hline 7 & 1 & 1 & 1 & 0 & 1 & 1 & 0 & 0 & 0 & 1 & 1 & 0 & 1 & 1 & 0 & 0 & 1 & -0.15496 \\
\hline 8 & 1 & 0 & 0 & 0 & 1 & 0 & 0 & 0 & 0 & 0 & 0 & 0 & 0 & 1 & 0 & 0 & 0 & 0.31763 \\
\hline 9 & 1 & 1 & 1 & 0 & 1 & 1 & 0 & 0 & 1 & 0 & 1 & 0 & 0 & 0 & 0 & 1 & 1 & 0.18074 \\
\hline 10 & 1 & 1 & 1 & 0 & 1 & 1 & 0 & 0 & 0 & 0 & 1 & 0 & 0 & 0 & 0 & 0 & 1 & 0.62959 \\
\hline 11 & 1 & 1 & 1 & 0 & 1 & 1 & 0 & 1 & 1 & 1 & 1 & 0 & 0 & 1 & 1 & 0 & 1 & -0.53526 \\
\hline 12 & 1 & 1 & 1 & 0 & 1 & 1 & 0 & 0 & 0 & 0 & 1 & 0 & $\mathbf{0}$ & 1 & 1 & 1 & 1 & -0.13324 \\
\hline 13 & 1 & 1 & 1 & 0 & 1 & 1 & 0 & 0 & 0 & 0 & 1 & 0 & 0 & 1 & 0 & $\mathbf{0}$ & 1 & 0.91885 \\
\hline 14 & 1 & 1 & 1 & $\mathbf{0}$ & 1 & 1 & 0 & 0 & 0 & 0 & 1 & 0 & $\mathbf{0}$ & 1 & 1 & 1 & 1 & -0.24724 \\
\hline 15 & 1 & 1 & 1 & 0 & 1 & 1 & 0 & 0 & 0 & 0 & 1 & 0 & 1 & 0 & 0 & $\mathbf{0}$ & 1 & -0.51421 \\
\hline 16 & 1 & 1 & 1 & 0 & 1 & 0 & 1 & 0 & 0 & 0 & 1 & 0 & 1 & 0 & 0 & 0 & 1 & -0.46192 \\
\hline 17 & 1 & 1 & 1 & 0 & 1 & 1 & 0 & 0 & 0 & 1 & 1 & 0 & 1 & 1 & 1 & 1 & 1 & -0.57442 \\
\hline 18 & 1 & 1 & 1 & 0 & 1 & 1 & 0 & 0 & $\mathbf{0}$ & 0 & 1 & 0 & 0 & 1 & 0 & $\mathbf{0}$ & 1 & 0.13172 \\
\hline 19 & 1 & $\mathbf{0}$ & 1 & 0 & 1 & 1 & 1 & 0 & $\mathbf{0}$ & 1 & 0 & 0 & $\mathbf{0}$ & 1 & 0 & o & 1 & -0.83135 \\
\hline 20 & 1 & 0 & 1 & 0 & 1 & 1 & 0 & 0 & 0 & 0 & 1 & 0 & 0 & 1 & 0 & 0 & 1 & -0.66245 \\
\hline 21 & 1 & 1 & 1 & 0 & 1 & 1 & 0 & 0 & 0 & 0 & 1 & 0 & 1 & 0 & 0 & 0 & 1 & -0.59375 \\
\hline 22 & 1 & 0 & 1 & 0 & 1 & 1 & 1 & 0 & 1 & 1 & 1 & 0 & 0 & 0 & 0 & 0 & 1 & -0.45752 \\
\hline 23 & 1 & 1 & 1 & 0 & 1 & 1 & 0 & 0 & 0 & 0 & 1 & 0 & 0 & 1 & 0 & 0 & 1 & -0.76344 \\
\hline 24 & 1 & 1 & 1 & 0 & 1 & 1 & 0 & 0 & 0 & 0 & 1 & 0 & 1 & 0 & 0 & 0 & 1 & -0.41666 \\
\hline
\end{tabular}

Note-The $z$ scores are the standarized rate of responding averaged over 8 subjects. 
tures, were easy to discriminate ( $z$ scores of about 0.9 ), but so was Slide 15, in which these features were absent.

\section{DISCUSSION}

Our results show that pigeons are capable of discriminating a geographic location depicted in a series of color slides. The fact that the subjects learned this discrimination quickly and displayed good transfer to slides viewed for the very first time suggests that the discrimination was a conceptual one. The poor performance of Honig and Stewart's (1988) "memorization control" subjects (for which $S+$ was a mixture of slides from the two locations, as was $\mathrm{S}-$ ) is also evidence for conceptual discrimination of place.

Although it has been well established by prior research that pigeons are capable of making conceptual discriminations of such natural stimuli as fish, people, and trees, our results, along with those of Honig and Stewart (1988) are apparently the first that show that pigeons are capable of making conceptual discriminations of more extended natural stimuli. While it may be exceedingly difficult (or impossible) physically to specify the defining features of the concept of tree, it seems that the specification of the defining features of geographic place will be even more difficult. The place our subjects discriminated was a geographic area centered on the UBC psychology building. Some of the slides were oriented away from this building; others were oriented toward the building. The building was not always present. Some slides were taken from the psychology building rooftop; others from nearby rooftops. Some were taken from rooftops about $.5 \mathrm{~km}$ away and some were taken from ground level. The only thing common in the set of positive slides was that they were taken within a general geographic area.

The fact that our pigeons quickly learned a discrimination of a particular spatial location and remembered this discrimination over a 60 -day retention interval stands in opposition to the general view in the literature that pigeons are not proficient in processing spatial information. Wilkie and Summers (1982) found very rapid forgetting of pecking-key location in a delayed matching-to-sample task. Bond, Cook, and Lamb (1981) studied pigeons on a radial maze and found little evidence that their subjects could remember which arms had been previously visited and depleted of food. Subsequent research that employed special training conditions (Roberts \& Van Veldhuizen, 1985), different mazes (Olson \& Maki, 1983; Wilkie, Spetch, \& Chew, 1981), or an open-field feeding environment (Spetch \& Edwards, 1986) demonstrated that pigeons have the capacity to remember recently visited locations. However, in most studies that have demonstrated a spatial memory ability in pigeons, retention of location information was relatively short lived. For example, Roberts and Van Veldhuizen (1985) found substantial forgetting with a 6-min retention interval.

It has been suggested that the reason for the pigeons' relatively poor performance on spatial memory tasks might be related to this species' foraging ecology. Because pigeons often seem to feed from areas that are not easily depleted during a single feeding bout, Bond, Cook, and Lamb (1981) have suggested that these birds may have evolved a tendency to return to locations where they had recently fed (a "win-stay" strategy) as well as a tendency to remember these locations (i.e., an accurate "reference memory," see Honig, 1978). Because of the way they feed, pigeons may not have developed a proficient "working memory." The pigeons' poor performance in spatial memory tasks may be due in part to the fact that many of these tasks require both a "win-shift"' strategy and an accurate working memory. Because our slidediscrimination task would seem to require only reference memory and not working memory, this difference may have been important in allowing our subjects to perform as well as they did. Support for this notion also comes from Roberts and Van Veldhuizen (1985, Experiment 6) and from our laboratory (Wilkie \& Willson, 1989), in which we have found that pigeons perform well on spatial tasks that require reference memory.

Another factor that may be important and may have contributed to the success of our subjects is the fact that our place is a natural one. Place as defined in our study could realistically be an actual feeding ground. That is, it would come as no surprise if feral pigeons learned to visit the psychology building routinely if a grain feeder was placed there. This naturalness may be an important reason why our spatial location was apparently remembered better than places defined by the locations of intra- and extramaze cues of a radial-arm maze located in a standard laboratory room.

The fact that our pigeons apparently recognized a geographic location depicted in a series of slides is consistent with the hypothesis that homing pigeons may use visual recognition of landmarks and terrain during homeward navigation, at least when close to home. However, our data must be interpreted cautiously. A demonstration that pigeons can visually recognize home does not necessarily mean that this ability is actually used (exclusively or even partially) when navigating home.

Another reason for being cautious in interpreting the implications of our results for understanding homing pigeons' navigation is the unexpected finding of relatively small differences between our homing and nonhoming subjects. If visual recognition of home is a significant stimulus for homers, one would expect homing pigeons to perform better on our tasks. Although the homing pigeons learned the discrimination more quickly and showed better transfer (at least during the initial transfer tests), this difference was statistically significant only during the first three transfer tests.

What is clear from our data is that nonhoming pigeons eventually become as good as trained homing pigeons at discriminating place. On the novel tray of slides, these subjects even outperformed the homing subjects. There are two interesting possible explanations for the convergence of the two groups. First, any special significance of the Home slides for the homing pigeons may depend upon continual (although intermittent) exposure to the real 
environment. Recall that outdoor flights for the homers were curtailed after the third transfer test. It is interesting to note that it was after this point that the groups converged. On the first three transfer tests, the homers performed significantly better than nonhomers.

Although we know of no other instances in which extraexperimental experience affected a discrimination, it is interesting to note that a process formally similar to experience-facilitated discrimination has been described by Gottlieb (1976). In discussing the possible roles of experience during perceptual development, Gottlieb identified three major types of developmental outcomes. In one, maintenance, experience is critical for the continued existence of a perceptual ability. In a second, induction, a perceptual process is absent until specific experiences occur. In the third, which may parallel our results, experience facilitates a partially developed ability. In future research it will be interesting to search for more conclusive evidence for experience-facilitated discrimination and to explore possible parallels between such an effect and the roles of experience in perceptual development. ${ }^{1}$

The second explanation of the similar abilities of homing and nonhoming pigeons to discriminate slides of a particular geographic location is that pigeons may visually discriminate a geographic place naturally by integrating a series of "snapshot" views of the place. That is, our nonhoming pigeons may have discriminated well because our procedure of presenting subjects with a succession of images might mimic a naturally occurring process. This notion is supported by the recent results of Honig and Stewart (1988), who trained pigeons to discriminate sets of slides taken at two distinctive locations on a university campus. In each location, slides were taken so as to cover $360^{\circ}$ from several different standpoints. Although their subjects had never physically been to these locations, Honig and Stewart's pigeons learned to discriminate the two locations quickly and showed good transfer to slides that contained both new views and new standpoints.

Although we suggest that discrimination of a geographic location can be formed simply from exposure to a series of snapshot views of the place (without actually experiencing the physical locations), it is important to stress that our study and that of Honig and Stewart (1988) are concerned with place recognition, which is clearly only a subset of spatial knowledge. It seems highly unlikely that nonexperienced pigeons learn anything of a functional nature during slide discriminations. That is, although pigeons exposed to slides of a place might recognize that place if it was physically encountered, they almost certainly would not be able to navigate in that space, know the location of food and the like, know how far one location is from another, or know where one place is relative to another. Experience seems essential for the acquisition of this type of information.

\section{REFERENCES}

BAKER, R. R. (1984). Bird navigation: The solution of a mystery? New York: Holmes \& Meier.
Benvenuti, S., Finschi, V. (1983). Pigeon homing: Combined effects of olfactory deprivation and visual impairment. Comparative Biochemistry \& Physiology, 76A, 719-723.

Bond, A. B., Cook, R. G., \& LAMB, M. R. (1981). Spatial memory and the performance of rats and pigeons in the radial-arm maze. Animal Learning \& Behavior, 9, 575-580.

CABE, P. A. (1976). Transfer of discrimination from solid objects to pictures by pigeons: A test of theoretical models of pictorial perception. Perception \& Psychophysics, 19, 545-550.

GotTlien, G. (1976). The roles of experience in the development of behavior and the nervous system. In G. Gottlieb (Ed.), Neural and behavioral specificity (pp. 25-54). New York: Academic Press.

Herrnstein, R. J. (1984). Objects, categories, and discriminative stimuli. In H. L. Roitblat, R. G. Bever, \& H. S. Terrace (Eds.), Animal cognition (pp. 233-261). Hillsdale, NJ: Erlbaum.

HoNiG, W. K. (1978). Studies of working memory in the pigeon. In S. H. Hulse, H. Fowler, \& W. K. Honig (Eds.), Cognitive processes in animal behavior (pp. 211-248). Hillsdale, NJ: Erlbaum.

Honig, W. K., \& Stewart, K. (1988). Pigeons can discriminate locations presented in pictures. Journal of the Experimental Analysis of Behavior, 50, 541-551.

Keeton, W. T. (1971). Magnets interfere with pigeon homing. Proceedings of the National Academy of Sciences, 68, 101-106.

LoOney, T. A., CoHEN, P. S. (1974). Pictorial target control of schedule-induced attack in White Carneaux pigeons. Journal of the Experimental Analysis of Behavior, 21, 504-571.

LUMSDEN, E. A. (1977). Generalization of an operant response to photographs and drawings/silhouettes of a three-dimensional object at various orientations. Bulletin of the Psychonomic Society, 10, 405-407.

Michener, M., Walcott, C. (1967). Homing of single pigeons: Analysis of tracks. Joumal of Experimental Biology, 47, 99-131.

MURRAY, B. (1967). Homing in pigeons. Science, 155, $1135-1136$.

OLson, D. J., MAKI, W. S. (1983). Characteristics of spatial memory in pigeons. Journal of Experimental Psychology: Animal Behavior Processes, 9, 266-280.

RoberTs, E. P., JR., \& WEIGL, P. D. (1984). Habitat preference in the dark-eyed junco (junco hyemalis): The role of photoperiod and dominance. Animal Behaviour, 32, 709-714.

Roberts, W. A., \& VAN Velohuizen, N. (1985). Spatial memory in pigeons on the radial maze. Joumal of Experimental Psychology: Animal Behavior Processes, 11, 241-260.

SCHMidT-Koenig, K., \& Schlichte, H. J. (1972). Homing in pigeons with impaired vision. Proceedings of the National Academy of Science USA, 69, 2446-2447.

SPETCH, M. L., EDWARDS, C. A. (1986). Spatial memory in pigeons (Columba livia) in an open-field feeding environment. Joumal of Comparative Psychology, 100, 266-278.

Vaughan, W., Jr., \& Greene, S. L. (1984). Pigeon visual memory capacity. Journal of Experimental Psychology: Animal Behavior Processes, 10, 256-271.

Wilkie, D. M., SPetch, M. L., Chew, L. (1981). The ring dove's short-term memory capacity for spatial information. Animal Behaviour, 29, 639-641.

Wilkie, D. M., \& Summers, R. J. (1982). Pigeons' spatial memory: Factors affecting delayed matching of key location. Journal of the Experimental Analysis of Behavior, 37, 45-56.

WilkIE, D. M., Willson, R. J. (1989). Pigeons' (Columba livia) spatial reference memory is stable over long retention intervals. Bulletin of the Psychonomic Society, 27, 271-273.

\section{NOTE}

1. In a study currently being conducted, we are finding evidence for experience-facilitated discrimination. Subjects that receive relevant outdoor experience (setting in the $S+$ location) outperform subjects that sit in an irrelevant location (one that is neither an $S+$ nor an $S$ - location). 